\title{
Daily Tourist Arrivals, Exchange Rates and Volatility for Korea and Taiwan
}

\author{
Chia-Lin Chang \\ Department of Applied Economics \\ National Chung Hsing University \\ Taichung, Taiwan
}

\author{
Michael McAleer \\ Econometric Institute \\ Erasmus School of Economics \\ Erasmus University Rotterdam \\ and \\ Tinbergen Institute \\ The Netherlands \\ and \\ Center for International Research on the Japanese Economy (CIRJE) \\ Faculty of Economics \\ University of Tokyo
}

EI 2009-41

November 2009

* For financial support, the first author wishes to thank the National Science Council, Taiwan, and the second author wishes to acknowledge the Australian Research Council and National Science Council, Taiwan. 


\begin{abstract}
Both domestic and international tourism are a major source of service export receipts for many countries worldwide, and is also increasingly important in Taiwan. One of the three leading tourism source countries for Taiwan is the Republic of Korea, which is a source of short haul tourism. Daily data from 1 January 1990 to 31 December 2008 are used to model the Korean Won / New Taiwan \$ exchange rate and tourist arrivals from Korea to Taiwan, as well as their associated volatility. The sample period includes the Asian economic and financial crises in 1997, and a significant part of the global financial crisis of 2008-09. Inclusion of the exchange rate allows approximate daily price effects on Korean tourism arrivals to Taiwan to be captured. The Heterogeneous Autoregressive (HAR) model is used to capture long memory properties in exchange rates and Korean tourist arrivals, to test whether alternative estimates of conditional volatility are sensitive to the long memory in the conditional mean, and to examine asymmetry and leverage in volatility. The empirical results show that the conditional volatility estimates are not sensitive to the long memory nature of the conditional mean specifications. The QMLE for the GARCH(1,1), GJR(1,1) and EGARCH(1,1) models for Korean tourist arrivals to Taiwan and the Korean Won / New Taiwan \$ exchange rate are statistically adequate and have sensible interpretations. Asymmetry (though not leverage) is found for several alternative HAR models.
\end{abstract}

Keywords: Korean tourist arrivals, exchange rates, approximate price effects, global financial crisis, Asian economic and financial crises, GARCH, GJR, EGARCH, HAR, long memory, asymmetry, leverage.

JEL Classifications: C22, F31, G18, G32. 


\section{Introduction}

Both domestic and international tourism are a major source of service export receipts for many countries worldwide, and is also increasingly important in Taiwan, an island in East Asia off the coast of mainland China, southwest of the main islands of Japan, directly west of Japan's Ryukyu Islands, and north to northwest of the Philippines. It is bound to the east by the Pacific Ocean, to the south by the South China Sea and the Luzon Strait, to the west by the Taiwan Strait, and to the north by the East China Sea. The island consists of steep mountains covered by tropical and subtropical vegetation. The main island of Taiwan is also known as Formosa (from the Portuguese Ilha Formosa, meaning "beautiful island”). The population is 23 million inhabitants (in 2005), consisting of 98\% Han Chinese and 2\% Aboriginal Taiwanese.

Taiwan's climate is marine tropical. The northern part of the island has a rainy season from January to late March during the southwest monsoon. The entire island succumbs to hot and humid weather from June until September, while October to December is arguably the most pleasant time of the year. Natural hazards, such as typhoons and earthquakes, are common in the region.

The three most important international tourism source countries to Taiwan are Japan, USA and Republic of Korea. More than three million international tourists visited Taiwan in 2008. The majority of the Taiwan tourist industry is supported by domestic tourism. As a result of Taiwan's extensive network of trains and highways, it is possible to traverse the country (north-south) in less than two hours by high speed train, and in a few hours by car. The most well known tourist attractions in Taiwan include the spectacular National Palace Museum (Taipei), amazing Night Markets (especially in Taipei), Taipei 101, formerly the world's tallest building, relaxing Sun Moon Lake (near Puli in the central highlands), and stunning Taroko National Park (east coast).

One of the most important purposes in attracting tourists is the amount that tourists spend. If the daily expenditure per tourist remains reasonably constant over the sample period, tourist arrivals and total tourism expenditure will be highly correlated. Moreover, the rate of growth in tourism expenditure and the rate of growth in tourist arrivals will then be very similar.

The primary purpose of the paper is to model Korean tourist arrivals and the Korean Won / New Taiwan \$ exchange rate, and their respective volatilities. Daily data from 1 January 1990 to 31 December 2008 are obtained from the National Immigration Agency of Taiwan for Korean tourist 
arrivals, and the Bloomberg database for the foreign exchange rate. By using daily data, we can approximate the modelling strategy and analysis to those applied to financial time series data. From a time series perspective, there are several reasons for using daily data (see, for example, McAleer (2009)). In particular, daily data allow an examination of whether the time series properties have changed, the time series behaviour at other frequencies can be obtained by aggregation of daily data, and the sample size is increased considerably. Moreover, the use of exchange rate data allows approximate daily price effects on Korean tourism arrivals to Taiwan to be captured.

The empirical results show that the time series of Korean tourist arrivals to Taiwan and the Won/NT\$ exchange rate are stationary. In addition, the estimated symmetric and asymmetric conditional volatility models, specifically the widely used GARCH, GJR and EGARCH models, all fit the data very well. In particular, the estimated models are able to account for the higher volatility persistence in both Korean tourist arrivals and the exchange rate that are observed at the end of the sample period, due primarily to the global financial crisis. The empirical second moment conditions typically support the statistical adequacy of the models for Korean tourist arrivals, and always support the adequacy of the empirical models of the exchange rate, so that statistical inferences are valid. Moreover, the estimates resemble those arising from financial time series data, with both short and long run persistence of shocks to Korean tourist arrivals and exchange rate, and asymmetric responses to positive and negative shocks of equal magnitude, though no leverage effects are observed. Therefore, volatility can be interpreted as risk associated with the growth rate in Korean tourist arrivals and the exchange rate.

The remainder of the paper is organized as follows. Section 2 presents the daily Korean tourist arrivals and exchange rate time series data. Section 3 performs unit root tests on both series. Section 4 discusses alternative long memory conditional mean and conditional volatility models for daily Korean tourist arrivals and the exchange rate. The estimated models and empirical results for the heterogeneous autoregressive (HAR) model are discussed in Section 5. Finally, some concluding remarks are given in Section 6.

\section{Data}

The data set comprises daily Korean tourist arrivals from 1 January 1990 to 31 December 2008, giving 6,940 observations obtained from the National Immigration Agency of Taiwan, and an equivalent number of observations on the Korean Won / New Taiwan \$ exchange rate that are 
obtained from the Bloomberg database: Taipei Foreign Exchange Market Development Foundation (URL: http://www.tpefx.com.tw).

From Figures 1-4 plot the daily Korean tourist arrivals and the Won / NT\$ exchange rate, as well as their respective volatilities, where volatility is defined as the squared deviation from the sample mean. There is higher volatility persistence at the end of the sample period, due primarily to the global financial crisis. The dominant observation for the exchange rate and its volatility occurred on 23 December 1997, at the height of the Asian economic and financial crises, when the Won / NT\$ exchange rate peaked at 60.24 (for further details on the global financial crisis see, for example, McAleer (2009, 2009a, 2009b, 2010).

Both Korean tourist arrivals to Taiwan and the Won / NT\$ daily exchange rate have varied considerably over the sample period, which suggests that the daily effects of the approximate price movements on tourism demand might be captured using an appropriate model. The exchange rate aside, there would seem to be considerable scope for a significant increase in Korean tourism to Taiwan. In order to manage tourism growth and its volatility, it is necessary to model adequately Korean tourist arrivals and their associated volatility.

In the next section we analyze the presence of a stochastic trend by applying unit root tests before modelling the time-varying volatility that is present in Korean tourist arrivals to Taiwan and the Won / NT\$ exchange rate series.

\section{Unit Root Tests}

Standard unit root tests based on the classic methods of Dickey and Fuller $(1979,1981)$ and Phillips and Perron (1988) are available in the econometric software package EViews 6.0, and are reported in Table 1. There is no evidence of a unit root in daily Korean tourist arrivals to Taiwan in the model with a constant and trend as the deterministic terms, or with just a constant. However, the outcome for the Won / NT\$ exchange rate is ambiguous, with the test statistics being significant for the model with just a constant, but insignificant for the model with a constant and deterministic time trend.

The correlation coefficients in Table 2 show that Korean tourist arrivals to Taiwan and the Won / NT\$ exchange rate, and their respective volatilities, are generally not highly correlated. In fact, the 
only three series that have meaningful correlations are the pairs Korean tourist arrivals to Taiwan and its associated volatility, the Won / NT\$ exchange rate and its associated volatility, and Korean tourist arrivals to Taiwan and the Won / NT\$ exchange rate, for which the correlation is -0.359 . Thus, Korean tourism demand and the approximate price effect through the Won / NT\$ exchange rate is negative, as expected. It is worth emphasizing that the negative correlation is with respect to daily data, which in itself is instructive.

These empirical results allow the use of Korean tourist arrivals data to Taiwan and the exchange rate between the two countries to estimate alternative univariate long memory conditional mean and conditional volatility models given in the next section.

\section{Conditional Mean and Conditional Volatility Models}

The alternative time series models to be estimated for the conditional means of the daily Korean tourist arrivals to Taiwan and the Won / NT\$ exchange rate, as well as their respective conditional volatilities, are discussed below. As shown in Figures 1 and 3, daily Korean tourist arrivals to Taiwan and the exchange rate show periods of high volatility, followed by others of relatively low volatility. One implication of this persistent volatility behaviour is that the assumption of (conditionally) homoskedastic residuals is inappropriate.

As discussed in Divino and McAleer (2009, 2010) and Chang et al. (2009), for example, for a wide range of data series in finance, international finance and tourism research, time-varying conditional variances can be explained empirically through the autoregressive conditional heteroskedasticity (ARCH) model, which was proposed by Engle (1982). When the time-varying conditional variance has both autoregressive and moving average components, this leads to the generalized $\operatorname{ARCH}(p, q)$, or $\operatorname{GARCH}(p, q)$, model of Bollerslev (1986). The lag structure of the appropriate GARCH model can be chosen by information criteria, such as those of Akaike and Schwarz, although it is very common to impose the widely estimated $\operatorname{GARCH}(1,1)$ specification in advance.

In the selected conditional volatility model, the residual series should follow a white noise process. $\mathrm{Li}$ et al. (2002) provide an extensive review of recent theoretical results for univariate and multivariate time series models with conditional volatility errors, and McAleer (2005) reviews a wide range of univariate and multivariate, conditional and stochastic, models of financial volatility. When Korean tourist arrivals data and the Korean Won / New Taiwan \$ exchange rate display 
persistence in volatility, as shown in Figures 2 and 4, respectively, it is natural to estimate alternative conditional volatility models.

The GARCH(1,1), GJR(1,1) and EGARCH(1,1) conditional volatility models have been estimated using monthly and daily tourist arrivals data in several papers, including Chan, Lim and McAleer (2005), Hoti, McAleer and Shareef (2005, 2007), Shareef and McAleer (2005, 2007, 2008), Divino and McAleer (2009, 2010), and Chang et al. (2009). However, these papers have not estimated any spillover effects between tourist arrivals and exchange rates, and hence have not been able to capture any approximate price effects affecting tourism demand.

The conditional volatility literature has been discussed extensively in recent years (see, for example, Li, Ling and McAleer (2002), McAleer (2005), and McAleer, Chan and Marinova (2007)). Consider the stationary AR(1)-GARCH(1,1) model for daily Korean tourist arrivals to Taiwan (or Korean Won / New Taiwan \$ exchange rate), $y_{t}$ :

$$
y_{t}=\phi_{1}+\phi_{2} y_{t-1}+\varepsilon_{t}, \quad\left|\phi_{2}\right|<1
$$

for $t=1, \ldots, n$, where the shocks (that is, movements in Korean tourist arrivals or Korean Won / New Taiwan \$ exchange rate) are given by:

$$
\begin{aligned}
& \varepsilon_{t}=\eta_{t} \sqrt{h_{t}}, \quad \eta_{t} \sim \operatorname{iid}(0,1) \\
& h_{t}=\omega+\alpha \varepsilon_{t-1}^{2}+\beta h_{t-1},
\end{aligned}
$$

and $\omega>0, \alpha \geq 0, \beta \geq 0$ are sufficient conditions to ensure that the conditional variance $h_{t}>0$. The AR(1) model in equation (1) can easily be extended to univariate or multivariate $\operatorname{ARMA}(p, q)$ processes (for further details, see Ling and McAleer (2003a)). In equation (2), the ARCH (or $\alpha$ ) effect indicates the short run persistence of shocks, while the GARCH (or $\beta$ ) effect indicates the contribution of shocks to long run persistence (namely, $\alpha+\beta$ ). The stationary $\operatorname{AR}(1)$ GARCH $(1,1)$ model can be modified to incorporate a non-stationary $\operatorname{ARMA}(p, q)$ conditional mean and a stationary GARCH $(r, s)$ conditional variance, as in Ling and McAleer (2003b). 
In equations (1) and (2), the parameters are typically estimated by the maximum likelihood method to obtain Quasi-Maximum Likelihood Estimators (QMLE) in the absence of normality of $\eta_{t}$, the conditional shocks (or standardized residuals). The conditional log-likelihood function is given as follows:

$$
\sum_{t=1}^{n} l_{t}=-\frac{1}{2} \sum_{t=1}^{n}\left(\log h_{t}+\frac{\varepsilon_{t}^{2}}{h_{t}}\right)
$$

The QMLE is efficient only if $\eta_{t}$ is normal, in which case it is the MLE. When $\eta_{t}$ is not normal, adaptive estimation can be used to obtain efficient estimators, although this can be computationally intensive. Ling and McAleer (2003b) investigated the properties of adaptive estimators for univariate non-stationary ARMA models with $\operatorname{GARCH}(r, s)$ errors. The extension to multivariate processes is complicated.

Since the GARCH process in equation (2) is a function of the unconditional shocks, the moments of $\varepsilon_{t}$ need to be investigated. Ling and McAleer (2003a) showed that the QMLE for GARCH(p,q) is consistent if the second moment of $\varepsilon_{t}$ is finite. For $\operatorname{GARCH}(p, q)$, Ling and $\operatorname{Li}$ (1997) demonstrated that the local QMLE is asymptotically normal if the fourth moment of $\varepsilon_{t}$ is finite, while Ling and McAleer (2003a) proved that the global QMLE is asymptotically normal if the sixth moment of $\varepsilon_{t}$ is finite. Using results from Ling and Li (1997) and Ling and McAleer (2002a, 2002b), the necessary and sufficient condition for the existence of the second moment of $\varepsilon_{t}$ for $\operatorname{GARCH}(1,1)$ is $\alpha+\beta<1$ and, under normality, the necessary and sufficient condition for the existence of the fourth moment is $(\alpha+\beta)^{2}+2 \alpha^{2}<1$.

As discussed in McAleer et al. (2007), Elie and Jeantheau (1995) and Jeantheau (1998) established that the log-moment condition was sufficient for consistency of the QMLE of a univariate GARCH(p,q) process (see Lee and Hansen (1994) for the proof in the case of GARCH(1,1)), while Boussama (2000) showed that the log-moment condition was sufficient for asymptotic normality. Based on these theoretical developments, a sufficient condition for the QMLE of GARCH(1,1) to be consistent and asymptotically normal is given by the log-moment condition, namely

$$
E\left(\log \left(\alpha \eta_{t}^{2}+\beta\right)\right)<0
$$


However, this condition is not easy to check in practice, even for the GARCH(1,1) model, as it involves the expectation of a function of a random variable and unknown parameters. Although the sufficient moment conditions for consistency and asymptotic normality of the QMLE for the univariate GARCH(1,1) model are stronger than their log-moment counterparts, the second moment condition is far more straightforward to check. In practice, the log-moment condition in equation (3) would be estimated by the sample mean, with the parameters $\alpha$ and $\beta$, and the standardized residual, $\eta_{t}$, being replaced by their QMLE counterparts.

The effects of positive shocks (or upward movements in daily Korean tourist arrivals) on the conditional variance, $h_{t}$, are assumed to be the same as the negative shocks (that is, downward movements in daily Korean tourist arrivals or the Korean Won / New Taiwan \$ exchange rate) in the symmetric GARCH model. In order to accommodate asymmetric behaviour, Glosten, Jagannathan and Runkle (1992) proposed the GJR model, for which GJR(1,1) is defined as follows:

$$
h_{t}=\omega+\left(\alpha+\gamma\left(\eta_{t-1}\right)\right) \varepsilon_{t-1}^{2}+\beta h_{t-1}
$$

where $\omega>0, \alpha \geq 0, \alpha+\gamma \geq 0, \beta \geq 0$ are sufficient conditions for $h_{t}>0$, and $I\left(\eta_{t}\right)$ is an indicator variable defined by:

$$
I\left(\eta_{t}\right)= \begin{cases}1, & \varepsilon_{t}<0 \\ 0, & \varepsilon_{t} \geq 0\end{cases}
$$

as $\eta_{t}$ has the same sign as $\varepsilon_{t}$. The indicator variable differentiates between positive and negative shocks of equal magnitude, so that asymmetric effects in the data are captured by the coefficient $\gamma$. For financial data, it is expected that $\gamma \geq 0$ because negative shocks increase risk by increasing the debt to equity ratio, but this interpretation need not hold for Korean tourism arrivals or the Korean Won / New Taiwan \$ exchange rate in the absence of a direct risk interpretation. The asymmetric effect, $\gamma$, measures the contribution of shocks to both short run persistence, $\alpha+\frac{\gamma}{2}$, and to long 
run persistence, $\alpha+\beta+\frac{\gamma}{2}$. It is not possible for leverage to be present in the GJR model, whereby negative shocks increase volatility and positive shocks of equal magnitude decrease volatility.

Ling and McAleer (2002a) showed that the regularity condition for the existence of the second moment for GJR(1,1) under symmetry of $\eta_{t}$ is given by:

$$
\alpha+\beta+\frac{1}{2} \gamma<1
$$

while McAleer et al. (2007) showed that the weaker log-moment condition for GJR(1,1) was given by:

$$
E\left(\ln \left[\left(\alpha+\gamma I\left(\eta_{t}\right)\right) \eta_{t}^{2}+\beta\right]\right)<0,
$$

which involves the expectation of a function of a random variable and unknown parameters.

An alternative model to capture asymmetric behaviour in the conditional variance is the Exponential GARCH (EGARCH(1,1)) model of Nelson (1991), namely:

$$
\log h_{t}=\omega+\alpha\left|\eta_{t-1}\right|+\gamma \eta_{t-1}+\beta \log h_{t-1}, \quad|\beta|<1
$$

where the parameters $\alpha, \beta$ and $\gamma$ have different interpretations from those in the GARCH(1,1) and GJR(1,1) models. If $\gamma=0$, there is no asymmetry, while $\gamma<0$, and $\gamma<\alpha<-\gamma$ are the conditions for leverage to exist, whereby negative shocks increase volatility and positive shocks of equal magnitude decrease volatility.

As noted in McAleer et al. (2007), there are some important differences between EGARCH and the previous two models, as follows: (i) EGARCH is a model of the logarithm of the conditional variance, which implies that no restrictions on the parameters are required to ensure $h_{t}>0$; (ii) moment conditions are required for the GARCH and GJR models as they are dependent on lagged unconditional shocks, whereas EGARCH does not require moment conditions to be established as it depends on lagged conditional shocks (or standardized residuals); (iii) Shephard (1996) observed 
that $|\beta|<1$ is likely to be a sufficient condition for consistency of QMLE for EGARCH(1,1); (iv) as the standardized residuals appear in equation (7), $|\beta|<1$ would seem to be a sufficient condition for the existence of moments; and ( $\mathrm{v}$ ) in addition to being a sufficient condition for consistency, $|\beta|<1$ is also likely to be sufficient for asymptotic normality of the QMLE of $\operatorname{EGARCH}(1,1)$.

Furthermore, EGARCH captures asymmetries differently from GJR. The parameters $\alpha$ and $\gamma$ in EGARCH(1,1) represent the magnitude (or size) and sign effects of the standardized residuals, respectively, on the conditional variance, whereas $\alpha$ and $\alpha+\gamma$ represent the effects of positive and negative shocks, respectively, on the conditional variance in GJR(1,1).

\section{Estimated Models and Analysis}

The Heterogenous Autoregressive (HAR) model was proposed by Corsi (2009) as an alternative to model and forecast realized volatilities, and is inspired by the Heterogenous Market Hypothesis of Muller, Dacorogna, Dav, Olsen, Pictet, and Ward (1993) and the asymmetric propagation of volatility between long and short horizons. Corsi (2009) showed that the actions of different types of market participants could lead to a simple restricted linear autoregressive model with the feature of considering volatilities realized over different time horizons. The heterogeneity of the model derives from the fact that different autoregressive structures are present at each time scale (for further details, see McAleer and Medeiros (2008)). In this section the HAR model is used to model total Korean tourist arrivals to Taiwan and the Korean Won / New Taiwan \$ exchange rate, together with the three conditional volatility models discussed in the previous section.

The alternative HAR $(h)$ models to be estimated to capture long memory are based on the following:

$$
y_{t, h}=\frac{y_{t}+y_{t-1}+y_{t-2}+\ldots+y_{t-h+1}}{h}
$$

where typical values of $h$ are one (daily data), seven (weekly data), and 28 (monthly data). In the empirical application, the three models to be estimated for Korean tourist arrivals to Taiwan and the Korean Won / New Taiwan \$ exchange rate, are as follows:

$$
y_{t}=\phi_{1}+\phi_{21} y_{t-1}+\phi_{22} x_{t-1}+\varepsilon_{t}
$$




$$
\begin{aligned}
& y_{t}=\phi_{1}+\phi_{21} y_{t-1}+\phi_{22} x_{t-1}+\phi_{31} y_{t-1,7}+\phi_{32} x_{t-1,7}+\varepsilon_{t} \\
& y_{t}=\phi_{1}+\phi_{21} y_{t-1}+\phi_{22} x_{t-1}+\phi_{31} y_{t-1,7}+\phi_{32} x_{t-1,7}+\phi_{41} y_{t-1,28}+\phi_{42} x_{t-1,28}+\varepsilon_{t} .
\end{aligned}
$$

The model sin equations (9)-(11) will be referred to as the $\operatorname{HAR}(1), \operatorname{HAR}(1,7)$ and $\operatorname{HAR}(1,7,28)$ models, respectively.

The conditional mean estimates in Tables 3-8 show that the $\operatorname{HAR}(1), \operatorname{HAR}(1,7)$ and $\operatorname{HAR}(1,7,28)$ estimates are all statistically significant, such that the long memory properties of Korean tourist arrivals to Taiwan and the Won / NT\$ exchange rate series are captured adequately through the statistical significance of the long memory variables.

The estimated conditional mean and conditional volatility models are given in Tables 3-8. The method used in estimation was the Marquardt algorithm. As shown in the unit root tests in Table 1, the Korean tourist arrivals to Taiwan series are stationary. These empirical results are supported by the estimates of the lagged dependent variables in the estimates of equations (9)-(11) for tourist arrivals, with the coefficients of the lagged dependent variable being significantly less than one in each of the estimated models.

As the second moment condition is typically less than unity in each case, the regularity conditions are generally satisfied, and hence the QMLE are consistent and asymptotically normal, and inferences are valid. The EGARCH(1,1) model is based on the standardized residuals, so the regularity condition is satisfied if $|\beta|<1$, and hence the QMLE are consistent and asymptotically normal (see, for example, McAleer et al. (2007)).

The GARCH(1,1) estimates in Tables 3-5 for the HAR(1), HAR(1,7) and HAR(1,7,28) models of Korean tourist arrivals to Taiwan suggest that the short run persistence of shocks lies between 0.04 and 0.093 , while the long run persistence is close to unity.

If positive and negative shocks to Korean tourist arrivals to Taiwan of a similar magnitude are treated asymmetrically, this can be evaluated in the GJR(1,1) model. The asymmetry coefficient is found to be negative and significant for the $\operatorname{HAR}(1), \operatorname{HAR}(1,7)$ and $\operatorname{HAR}(1,7,28)$ models, which indicates that decreases in Korean tourist arrivals decrease volatility. Therefore, shocks to Korean tourist arrivals to Taiwan can be interpreted as risk associated with Korean tourist arrivals. 
Although asymmetry is observed for the $\operatorname{HAR}(1), \operatorname{HAR}(1,7)$ and $\operatorname{HAR}(1,7,28)$ models, there is no evidence of leverage. These empirical results show that the conditional volatility estimates are not sensitive to the long memory nature of the conditional mean specifications. As the second moment condition, $\alpha+\beta+\frac{1}{2} \gamma<1$, is typically satisfied, the log-moment condition is necessarily satisfied, so that the QMLE are consistent and asymptotically normal. Therefore, statistical inference using the asymptotic normal distribution is valid, and the asymmetric GJR(1,1) estimates are statistically significant.

The interpretation of the EGARCH model is in terms of the logarithm of volatility. For Korean tourist arrivals to Taiwan, each of the $\operatorname{EGARCH}(1,1)$ estimates is statistically significant for the $\operatorname{HAR}(1), \operatorname{HAR}(1,7)$ and $\operatorname{HAR}(1,7,28)$ models, with both the size effect, $\alpha$, and the sign effect, $\gamma$, being positive in all three cases. The coefficient of the lagged dependent variable, $\beta$, is estimated to be less than unity, which suggests that the statistical properties of the QMLE for EGARCH(1,1) will be consistent and asymptotically normal. These empirical results show that the volatility in the shocks to Korean tourist arrivals to Taiwan are not sensitive to the long memory nature of the conditional mean specifications.

Overall, the QMLE for the GARCH(1,1), GJR(1,1) and $\operatorname{EGARCH}(1,1)$ models for Korean tourist arrivals to Taiwan are statistically adequate and have sensible interpretations. However, asymmetry (though not leverage) was found for the $\operatorname{HAR}(1)$, $\operatorname{HAR}(1,7)$ and $\operatorname{HAR}(1,7,28)$ models.

The GARCH(1,1) estimates in Tables 6-8 for the HAR(1), HAR(1,7) and HAR(1,7,28) models of the Won / NT\$ exchange rate suggest that the short run persistence of shocks lies between 0.068 and 0.081 , while the long run persistence is close to unity. The second moment regularity condition is satisfied in all cases, so that statistical inference using the asymptotic normal distribution is valid.

The GJR(1,1) model treats positive and negative shocks to the Won / NT\$ exchange rate of a similar magnitude asymmetrically. The asymmetry coefficient is found to be negative and significant for the $\operatorname{HAR}(1), \operatorname{HAR}(1,7)$ and $\operatorname{HAR}(1,7,28)$ models, which indicates that decreases in the Won / NT\$ exchange rate decrease volatility. Therefore, shocks to the exchange rate can be interpreted as financial risk. Although asymmetry is observed for the $\operatorname{HAR}(1), \operatorname{HAR}(1,7)$ and $\operatorname{HAR}(1,7,28)$ models, there is no evidence of leverage. These empirical results show that the conditional volatility estimates are not sensitive to the long memory nature of the conditional mean 
specifications. As the second moment condition is satisfied in all cases, the log-moment condition is necessarily satisfied, so that the QMLE are consistent and asymptotically normal. Therefore, statistical inference using the asymptotic normal distribution is valid.

For the Won / NT\$ exchange rate, each of the EGARCH(1,1) estimates is statistically significant for the $\operatorname{HAR}(1), \operatorname{HAR}(1,7)$ and $\operatorname{HAR}(1,7,28)$ models, with both the size effect, $\alpha$, and the sign effect, $\gamma$, being positive in all three cases. The coefficient of the lagged dependent variable, $\beta$, is estimated to be less than unity, which suggests that the statistical properties of the QMLE for EGARCH(1,1) will be consistent and asymptotically normal. These empirical results show that the volatility in the shocks to the exchange rate are not sensitive to the long memory nature of the conditional mean specifications.

Overall, the QMLE for the GARCH(1,1), GJR(1,1) and EGARCH(1,1) models for the Won / NT\$ exchange rate are statistically adequate and have sensible interpretations. As in the case of Korean tourist arrivals to Taiwan, asymmetry (though not leverage) was found for the $\operatorname{HAR}(1), \operatorname{HAR}(1,7)$ and $\operatorname{HAR}(1,7,28)$ models of the exchange rate.

\section{Concluding Remarks}

Although it is not yet one of the most important industries in Taiwan, an island in East Asia off the coast of mainland China, the three most important tourism source countries for Taiwan are Japan, USA and the Republic of Korea, which reflect short and long haul tourist destinations.

As Korean tourism to Taiwan has not yet achieved the status of an important economic activity for Taiwan's finances, there is significant room for improvement in tourism receipts from this tourism source country. However, the potential negative impacts of mass tourism on the environment, and hence on future Korean tourism demand, must be managed appropriately. In order to manage Korean tourism growth, it is necessary to model adequately Korean tourist arrivals and their associated volatility. As the exchange rate allows approximate daily price effects on Korean tourism arrivals to Taiwan to be captured, it is also necessary to analyse the Korean Won / New Taiwan \$ exchange rate, as well as its associated volatility.

The paper examined daily Korean tourist arrivals to Taiwan from 1 January 1990 to 31 December 2008, as obtained from the National Immigration Agency of Taiwan, and the Korean Won / New 
Taiwan \$ exchange rate, as obtained from the Bloomberg database. The Heterogeneous Autoregressive (HAR) model was used to capture the long memory properties in both data series. The empirical results showed that the time series of Korean tourist arrivals to Taiwan and the Won / NT\$ exchange rate were stationary. In addition, the estimated symmetric and asymmetric conditional volatility models, specifically the widely used GARCH, GJR and EGARCH models all fit the data extremely well. In particular, the estimated models were able to account for the higher volatility persistence that was observed at the end of the sample period, due primarily to the global financial crisis.

The empirical second moment condition also generally supported the statistical adequacy of the models of Korean tourist arrivals to Taiwan, and always so for the Won / NT\$ exchange rate, so that statistical inferences were valid. Moreover, the estimates resembled those arising from financial time series data, with both short and long run persistence of shocks, and asymmetric effects of positive and negative shocks of equal magnitude to volatility. Although asymmetry was observed for the $\operatorname{HAR}(1), \operatorname{HAR}(1,7)$ and $\operatorname{HAR}(1,7,28)$ models, there was no evidence of leverage. Overall, volatility can be interpreted as risk associated with shocks to Korean tourist arrivals to Taiwan and the Korean Won / New Taiwan \$ exchange rate. 


\section{References}

Bollerslev, T. (1986), Generalised autoregressive conditional heteroscedasticity, Journal of Econometrics, 31, 307-327.

Boussama, F. (2000), Asymptotic normality for the quasi-maximum likelihood estimator of a GARCH model, Comptes Rendus de l'Academie des Sciences, Serie I, 331, 81-84 (in French).

Chan, F., C. Lim and M. McAleer (2005), Modelling multivariate international tourism demand and volatility, Tourism Management, 26, 459-471.

Chang, C.-L., M. McAleer and D. Slottje (2009), Modelling international tourist arrivals and volatility: An application to Taiwan, in D. Slottje (ed.), Quantifying Consumer Preferences, Contributions to Economic Analysis Series, Volume 288, Emerald Group Publishing, 2009, chapter 11 , pp. 303-320.

Corsi, F. (2009), A simple approximate long-memory model of realized volatility, Journal of Financial Econometrics, 7, 174-196.

Dickey, D.A. and W.A. Fuller (1979), Distribution of the estimators for autoregressive time series with a unit root, Journal of the American Statistical Association, 74, 427-431.

Dickey, D.A. and W.A. Fuller (1981), Likelihood ratio statistics for autoregressive time series with a unit root, Econometrica, 49, 1057-1072.

Divino, J.A. and M. McAleer (2009), Modelling and forecasting sustainable international tourism demand for the Brazilian Amazon, Environmental Modelling \& Software, 24, 1411-1419.

Divino, J.A. and M. McAleer (2010), Modelling the growth and volatility in daily international mass tourism to Peru, to appear in Tourism Management.

Elie, L. and T. Jeantheau (1995), Consistency in heteroskedastic models, Comptes Rendus de l’Académie des Sciences, Série I, 320, 1255-1258 (in French).

Engle, R.F. (1982), Autoregressive conditional heteroscedasticity with estimates of the variance of United Kingdom inflation, Econometrica, 50, 987-1007.

Glosten, L., R. Jagannathan and D. Runkle (1992), On the relation between the expected value and volatility of nominal excess return on stocks, Journal of Finance, 46, 1779-1801. 
Hoti, S., M. McAleer and R. Shareef (2005), Modelling country risk and uncertainty in small island tourism economies, Tourism Economics, 11, 159-183.

Hoti, S., M. McAleer and R. Shareef (2007), Modelling international tourism and country risk spillovers for Cyprus and Malta, Tourism Management, 28, 1472-84.

Jeantheau, T. (1998), Strong consistency of estimators for multivariate ARCH models, Econometric Theory, 14, 70-86.

Lee, S.W. and B.E. Hansen (1994), Asymptotic theory for the GARCH(1,1) quasi-maximum likelihood estimator, Econometric Theory, 10, 29-52.

Li, W.K., S. Ling and M. McAleer (2002), Recent theoretical results for time series models with GARCH errors, Journal of Economic Surveys, 16, 245-269. Reprinted in M. McAleer and L. Oxley (eds.), Contributions to Financial Econometrics: Theoretical and Practical Issues, Blackwell, Oxford, 2002, pp. 9-33.

Ling, S. and W.K. Li (1997), On fractionally integrated autoregressive moving-average models with conditional heteroskedasticity, Journal of the American Statistical Association, 92, 11841194.

Ling, S. and M. McAleer (2002a), Stationarity and the existence of moments of a family of GARCH processes, Journal of Econometrics, 106, 109-117.

Ling, S. and M. McAleer (2002b), Necessary and sufficient moment conditions for the GARCH(r,s) and asymmetric power GARCH(r,s) models, Econometric Theory, 18, 722-729.

Ling, S. and M. McAleer, (2003a), Asymptotic theory for a vector ARMA-GARCH model, Econometric Theory, 19, 278-308.

Ling, S. and M. McAleer (2003b), On adaptive estimation in nonstationary ARMA models with GARCH errors, Annals of Statistics, 31, 642-674.

McAleer, M. (2005), Automated inference and learning in modeling financial volatility, Econometric Theory, 21, 232-261.

McAleer, M. (2009), The Ten Commandments for optimizing value-at-risk and daily capital charges, Journal of Economic Surveys, 23, 831-849.

McAleer, M., F. Chan and D. Marinova (2007), An econometric analysis of asymmetric volatility: theory and application to patents, Journal of Econometrics, 139, 259-284. 
McAleer, M., J.-A. Jiménez-Martin and T. Perez Amaral (2009a), Has the Basel II Accord encouraged risk management during the 2008-09 financial crisis?, Available at SSRN: http://ssrn.com/abstract=1397239.

McAleer, M., J.-A. Jiménez-Martin and T. Perez Amaral (2009b), Optimal risk management before, during and after the 2008-09 financial crisis, Available at SSRN: http://ssrn.com/abstract=1473191.

McAleer, M., J.-A. Jiménez-Martin and T. Perez Amaral (2010), What happened to risk management during the 2008-09 financial crisis?, to appear in R.W. Kolb (ed.), Lessons from the Financial Crisis: Causes, Consequences, and Our Economic Future, Wiley, New York, 2010, Available at SSRN: http://ssrn.com/abstract=1442034.

McAleer, M., T. Perez Amaral and J.-A. Jiménez-Martin (2009), “A decision rule to minimize daily capital charges in forecasting value-at-risk”, to appear in Journal of Forecasting, Available at SSRN: http://ssrn.com/abstract=1349844.

McAleer, M. and M. Medeiros (2008), A multiple regime smooth transition heterogeneous autoregressive model for long memory and asymmetries, Journal of Econometrics, 147(1), 2008, 104-119.

McAleer, M and B. da Veiga (2008a), Forecasting value-at-risk with a parsimonious portfolio spillover GARCH (PS-GARCH) model, Journal of Forecasting, 27, 1-19.

McAleer, M and B. da Veiga (2008b), Single-index and portfolio models for forecasting value-atrisk thresholds, Journal of Forecasting, 27, 217-235.

Muller, U., M. Dacorogna, R. Dav, R. Olsen, O. Pictet and J. ward (1993), Fractals and intrinsic time - a challenge to econometricians," in Proceedings of the XXXIXth International AEA Conference on Real Time Econometrics.

Nelson, D.B. (1991), Conditional heteroscedasticity in asset returns: a new approach, Econometrica, 59, 347-370.

Phillips, P.C.B. and P. Perron (1988), Testing for a unit root in time series regression, Biometrika, 75, 335-346.

Shareef, R. and M. McAleer (2005), Modelling international tourism demand and volatility in small island tourism economies, International Journal of Tourism Research, 7, 313-333. 
Shareef, R. and M. McAleer (2007), Modelling the uncertainty in international tourist arrivals to the Maldives, Tourism Management, 28, 23-45.

Shareef, R. and M. McAleer (2008), Modelling international tourism demand and uncertainty in Maldives and Seychelles: a portfolio approach, Mathematics and Computers in Simulation, 78, 459-68.

Shephard, N. (1996), Statistical aspects of ARCH and stochastic volatility, in O.E. BarndorffNielsen, D.R. Cox and D.V. Hinkley (eds.), Statistical Models in Econometrics, Finance and Other Fields, Chapman \& Hall, London, pp. 1-67. 
Figure 1. Daily Korean Tourist Arrivals to Taiwan

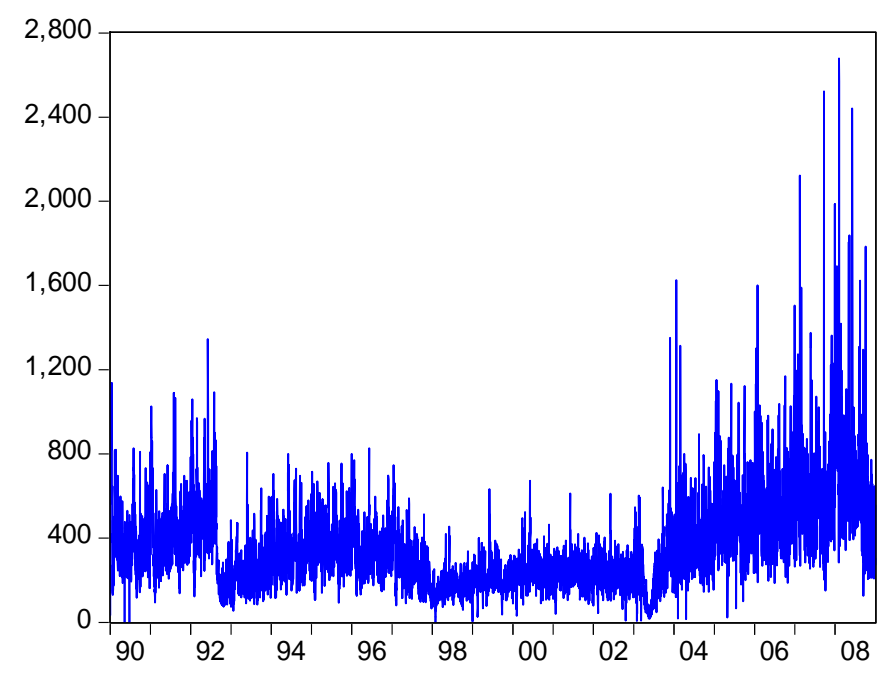

Figure 2. Volatility of Daily Korean Tourist Srrivals to Taiwan

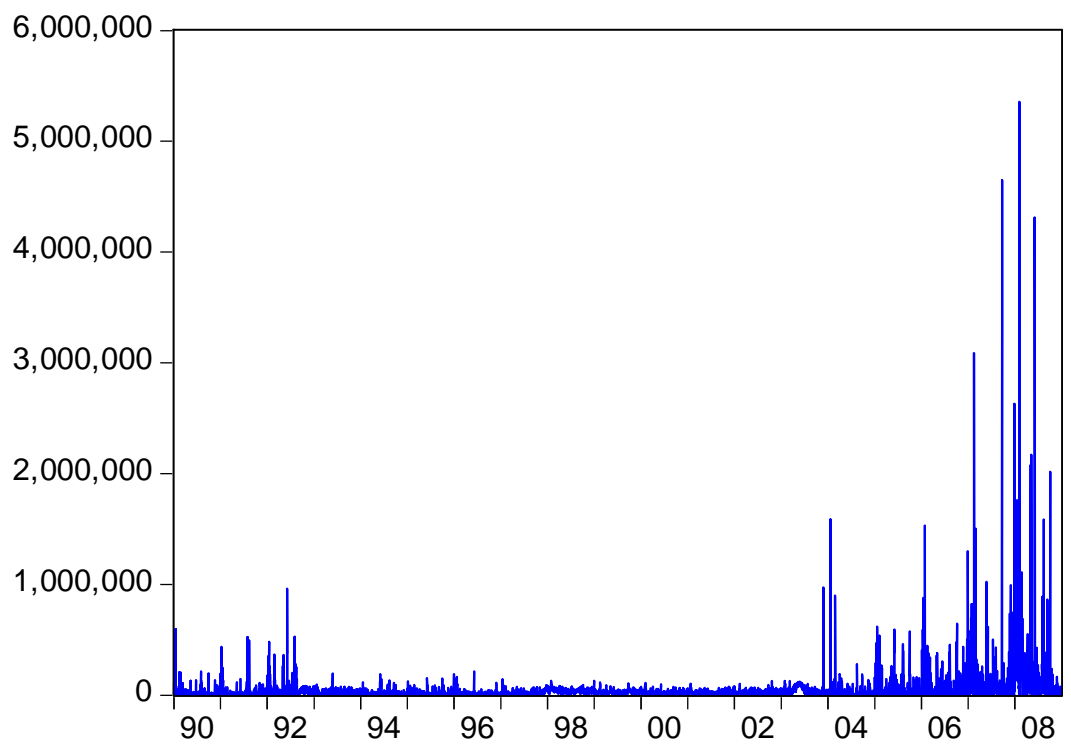


Figure 3. Daily Exchange Rate of Korean Won / New Taiwan \$

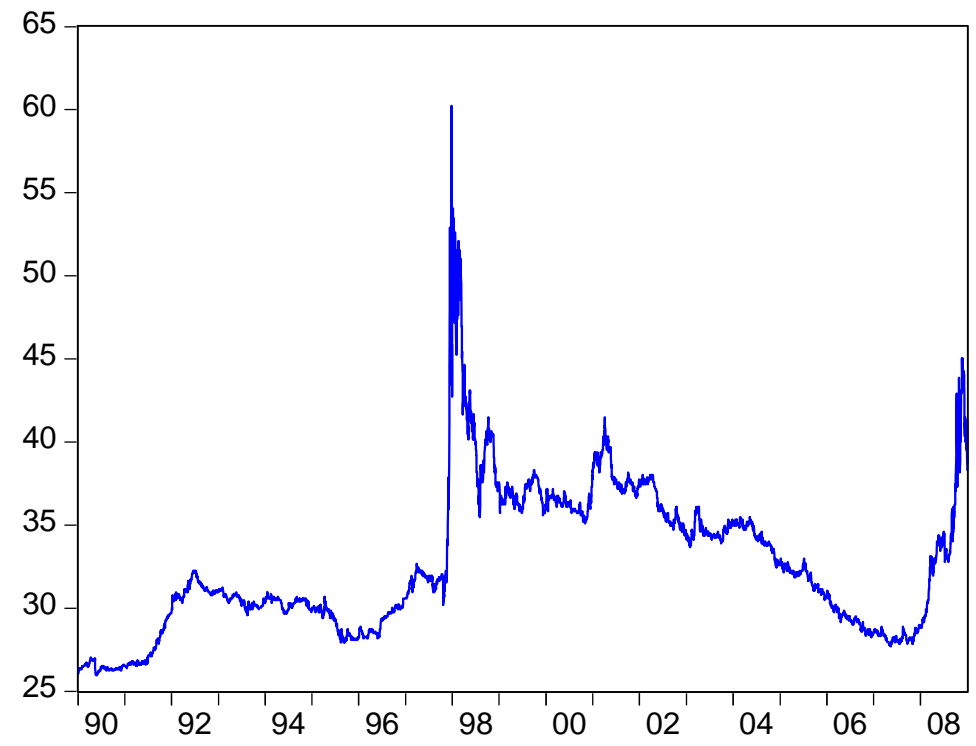

Figure 4. Volatility of Daily Exchange Rate of Korean Won / New Taiwan \$

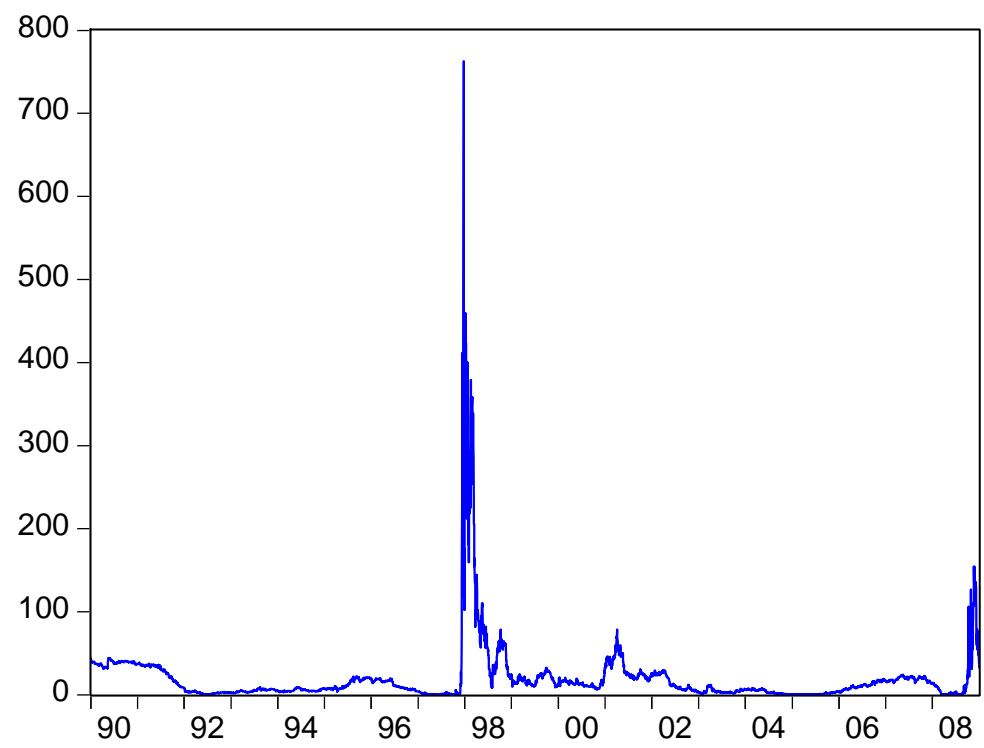


Table 1. Unit Root Tests

\begin{tabular}{lcccc}
\hline Variables & $\mathrm{ADF}$ & $\mathrm{PP}$ & $\mathrm{ADF}$ & $\mathrm{PP}$ \\
& $\mathrm{Z}=\{1\}$ & $\mathrm{Z}=\{1\}$ & $\mathrm{Z}=\{1, \mathrm{t}\}$ & $\mathrm{Z}=\{1, \mathrm{t}\}$ \\
\hline $\begin{array}{l}\text { Korean Tourist } \\
\text { Arrivals to Taiwan }\end{array}$ & $-4.023^{* *}$ & $-74.169^{* *}$ & $-4.386^{* *}$ & $-77.179^{* *}$ \\
& & & & \\
\hline Variable & $\mathrm{ADF}$ & $\mathrm{PP}$ & $\mathrm{ADF}$ & $\mathrm{PP}$ \\
& $\mathrm{Z}=\{1\}$ & $\mathrm{Z}=\{1\}$ & $\mathrm{Z}=\{1, \mathrm{t}\}$ & $\mathrm{Z}=\{1, \mathrm{t}\}$ \\
\hline \multirow{2}{*}{ Exchange Rate } & $-2.800^{*}$ & $-2.800^{*}$ & -2.938 & -2.996 \\
& & & & \\
\hline
\end{tabular}

Notes: The critical values for the ADF test are $-3.43(-2.57)$ at the $1 \%(10 \%)$ level when $Z=\{1\}$, and -3.95 $(-3.13)$ at the $1 \%(10 \%)$ level when $Z=\{1, t\}$. The critical values for the PP test are $-3.43(-2.57)$ at the $1 \%$ (10\%) level when $Z=\{1\}$, and $-3.95(-3.13)$ at the $1 \%(10 \%)$ level when $Z=\{1, t\}$.

** and * denote the null hypothesis of a unit root is rejected at the $1 \%$ and $10 \%$ levels, respectively.

Table 2. Correlation Coefficients

\begin{tabular}{|c|c|c|c|c|}
\hline Variables & $\begin{array}{c}\text { Korean Tourist } \\
\text { Arrivals to Taiwan }\end{array}$ & Exchange rate & $\begin{array}{c}\text { Volatility of } \\
\text { Korean Tourist } \\
\text { Arrivals to Taiwan }\end{array}$ & $\begin{array}{c}\text { Volatility of Korean } \\
\text { Exchange rate }\end{array}$ \\
\hline $\begin{array}{l}\text { Korean Tourist } \\
\text { Arrivals to Taiwan }\end{array}$ & 1.000 & -0.359 & 0.612 & -0.155 \\
\hline Exchange rate & -0.359 & 1.000 & -0.043 & 0.528 \\
\hline $\begin{array}{l}\text { Volatility of } \\
\text { Korean Tourist } \\
\text { Arrivals to Taiwan }\end{array}$ & 0.612 & -0.043 & 1.000 & -0.009 \\
\hline $\begin{array}{l}\text { Volatility of } \\
\text { Exchange rate }\end{array}$ & -0.155 & 0.528 & -0.009 & 1.000 \\
\hline
\end{tabular}

Note: The exchange rate refers to the Korean Won / New Taiwan \$. 
Table 3: Estimated Conditional Mean (HAR(1)) and Conditional Volatility Models for Korean Tourist Arrivals to Taiwan

\begin{tabular}{|c|c|c|c|}
\hline Parameters & GARCH & GJR & EGARCH \\
\hline$\phi_{1}$ & $\begin{array}{c}272.875^{* *} \\
(10.393)\end{array}$ & $\begin{array}{c}261.765 * * \\
(11.053)\end{array}$ & $\begin{array}{c}257.349 * * \\
(10.539)\end{array}$ \\
\hline$\phi_{21}$ & $\begin{array}{l}0.613^{* *} \\
(0.009)\end{array}$ & $\begin{array}{c}0.621^{* *} \\
(0.009)\end{array}$ & $\begin{array}{c}0.619 * * \\
(0.009)\end{array}$ \\
\hline$\phi_{22}$ & $\begin{array}{c}-4.873^{* *} \\
(0.260)\end{array}$ & $\begin{array}{c}-0.467 * * \\
(0.282)\end{array}$ & $\begin{array}{c}-4.449 * * \\
(0.270)\end{array}$ \\
\hline$\omega$ & $\begin{array}{l}19.696^{*} \\
(6.575)\end{array}$ & $\begin{array}{c}56.872^{* *} \\
(10.601)\end{array}$ & $\begin{array}{l}-0.006 \\
(0.012)\end{array}$ \\
\hline GARCH/GJR $\alpha$ & $\begin{array}{l}0.045^{* *} \\
(0.002)\end{array}$ & $\begin{array}{c}0.055^{* *} \\
(0.003)\end{array}$ & -- \\
\hline GARCH/GJR $\beta$ & $\begin{array}{c}0.956 * * \\
(0.002)\end{array}$ & $\begin{array}{c}0.952 * * \\
(0.002)\end{array}$ & -- \\
\hline GJR $\gamma$ & -- & $\begin{array}{c}-0.023^{* *} \\
(0.004)\end{array}$ & -- \\
\hline EGARCH $\alpha$ & -- & -- & $\begin{array}{c}0.110^{* *} \\
(0.005)\end{array}$ \\
\hline EGARCH $\gamma$ & -- & -- & $\begin{array}{c}0.032 * * \\
(0.003)\end{array}$ \\
\hline EGARCH $\beta$ & -- & -- & $\begin{array}{c}0.992 * * \\
(0.001) \\
\end{array}$ \\
\hline \multicolumn{4}{|l|}{ Diagnostics } \\
\hline AIC & 12.4407 & 12.438 & 12.435 \\
\hline $\mathrm{BIC}$ & 12.4467 & 12.445 & 12.442 \\
\hline $\begin{array}{l}\text { Jarque-Bera } \\
\text { [p-value] }\end{array}$ & $\begin{array}{c}3519.13 \\
{[0.000]}\end{array}$ & $\begin{array}{c}3224.96 \\
{[0.000]}\end{array}$ & $\begin{array}{c}3643.84 \\
{[0.000]}\end{array}$ \\
\hline $\begin{array}{l}\text { Causality t test } \\
\text { [p-value] }\end{array}$ & $\begin{array}{c}-4.873 \\
{[0.000]}\end{array}$ & $\begin{array}{l}-4.067 \\
{[0.000]}\end{array}$ & $\begin{array}{l}-4.449 \\
{[0.000]}\end{array}$ \\
\hline
\end{tabular}

Notes: The dependent variable is Korean tourist arrivals to Taiwan. Numbers in parentheses are standard errors. The log-moment condition is necessarily satisfied as the second moment condition is satisfied for GJR model. AIC and BIC denote the Akaike Information Criterion and Schwarz Bayesian Information Criterion, respectively. ** and * denote the estimated coefficients are statistically significant at the $1 \%$ and $5 \%$ levels, respectively. 
Table 4: Estimated Conditional Mean $(\operatorname{HAR}(1,7))$ and Conditional Volatility Models for Korean Tourist Arrivals to Taiwan

\begin{tabular}{|c|c|c|c|}
\hline Parameters & GARCH & GJR & EGARCH \\
\hline$\phi_{1}$ & $\begin{array}{c}61.610 * * \\
(9.436)\end{array}$ & $\begin{array}{l}\text { 60.898** } \\
(11.318)\end{array}$ & $\begin{array}{c}42.926 * * \\
(7.036)\end{array}$ \\
\hline$\phi_{21}$ & $\begin{array}{c}0.243^{* *} \\
(0.013)\end{array}$ & $\begin{array}{c}0.257^{* *} \\
(0.013)\end{array}$ & $\begin{array}{c}0.269 * * \\
(0.012)\end{array}$ \\
\hline$\phi_{22}$ & $\begin{array}{l}-1.679 \\
(2.181)\end{array}$ & $\begin{array}{l}-1.476 \\
(2.293)\end{array}$ & $\begin{array}{c}-0.741 \\
(1.605)\end{array}$ \\
\hline$\phi_{31}$ & $\begin{array}{l}0.680^{* *} \\
(0.017)\end{array}$ & $\begin{array}{c}0.658 * * \\
(0.017)\end{array}$ & $\begin{array}{c}0.648^{* *} \\
(0.014)\end{array}$ \\
\hline$\phi_{32}$ & $\begin{array}{c}0.537 \\
(2.192) \\
\end{array}$ & $\begin{array}{c}0.426 \\
(2.307) \\
\end{array}$ & $\begin{array}{c}0.199 \\
(1.598)\end{array}$ \\
\hline$\omega$ & $\begin{array}{c}41.957 * * \\
(9.983)\end{array}$ & $\begin{array}{c}42.129 * * \\
(8.193)\end{array}$ & $\begin{array}{c}0.011 \\
(0.009)\end{array}$ \\
\hline GARCH/GJR $\alpha$ & $\begin{array}{c}0.093^{* *} \\
(0.003)\end{array}$ & $\begin{array}{c}0.088 * * \\
(0.004)\end{array}$ & -- \\
\hline GARCH/GJR $\beta$ & $\begin{array}{c}0.915^{* *} \\
(0.003)\end{array}$ & $\begin{array}{c}0.931^{* *} \\
(0.002)\end{array}$ & -- \\
\hline GJR $\gamma$ & -- & $\begin{array}{c}-0.037 * * \\
(0.006)\end{array}$ & -- \\
\hline EGARCH $\alpha$ & -- & -- & $\begin{array}{c}0.093 * * \\
(0.005)\end{array}$ \\
\hline EGARCH $\gamma$ & -- & -- & $\begin{array}{l}0.083 * * \\
(0.004)\end{array}$ \\
\hline EGARCH $\beta$ & -- & -- & $\begin{array}{l}0.991 * * \\
(0.001) \\
\end{array}$ \\
\hline \multicolumn{4}{|l|}{ Diagnostics } \\
\hline AIC & 12.270 & 12.269 & 12.255 \\
\hline BIC & 12.278 & 12.278 & 12.264 \\
\hline $\begin{array}{l}\text { Jarque-Bera } \\
\text { [p-value] }\end{array}$ & $\begin{array}{c}11882.84 \\
{[0.000]}\end{array}$ & $\begin{array}{c}12951.53 \\
{[0.000]}\end{array}$ & $\begin{array}{c}16801.33 \\
{[0.000]}\end{array}$ \\
\hline $\begin{array}{l}\text { Causality F test } \\
\text { [p-value] }\end{array}$ & $\begin{array}{l}12.977 \\
{[0.000]} \\
\end{array}$ & $\begin{array}{c}7.689 \\
{[0.0005]} \\
\end{array}$ & $\begin{array}{c}5.811 \\
{[0.003]}\end{array}$ \\
\hline
\end{tabular}

Notes: The dependent variable is Korean tourist arrivals to Taiwan. Numbers in parentheses are standard errors. AIC and BIC denote the Akaike Information Criterion and Schwarz Bayesian Information Criterion, respectively. ** denotes the estimated coefficient is statistically significant at the $1 \%$ level. 
Table 5: Estimated Conditional Mean $(\operatorname{HAR}(1,7,28))$ and Conditional Volatility Models for Korean Tourist Arrivals to Taiwan

\begin{tabular}{|c|c|c|c|}
\hline Parameters & GARCH & GJR & EGARCH \\
\hline$\phi_{1}$ & $\begin{array}{c}42.698 * * \\
(9.703)\end{array}$ & $\begin{array}{c}43.168 * * \\
(11.156)\end{array}$ & $\begin{array}{c}27.275^{* *} \\
(4.689)\end{array}$ \\
\hline$\phi_{21}$ & $\begin{array}{c}0.244^{* *} \\
(0.013)\end{array}$ & $\begin{array}{c}0.253^{* *} \\
(0.013)\end{array}$ & $\begin{array}{l}0.274^{* *} \\
(0.011)\end{array}$ \\
\hline$\phi_{22}$ & $\begin{array}{l}-1.532 \\
(2.202)\end{array}$ & $\begin{array}{l}-1.418 \\
(2.254)\end{array}$ & $\begin{array}{c}0.003 \\
(1.424)\end{array}$ \\
\hline$\phi_{31}$ & $\begin{array}{l}0.565^{* *} \\
(0.025)\end{array}$ & $\begin{array}{l}0.558^{* *} \\
(0.025)\end{array}$ & $\begin{array}{l}0.554 * * \\
(0.020)\end{array}$ \\
\hline$\phi_{32}$ & $\begin{array}{l}-0.270 \\
(2.979)\end{array}$ & $\begin{array}{l}-0.275 \\
(3.045)\end{array}$ & $\begin{array}{c}0.128 \\
(1.629)\end{array}$ \\
\hline$\phi_{41}$ & $\begin{array}{l}0.142 * * \\
(0.021)\end{array}$ & $\begin{array}{c}0.134^{* *} \\
(0.022)\end{array}$ & $\begin{array}{l}0.115^{* *} \\
(0.015)\end{array}$ \\
\hline$\phi_{42}$ & $\begin{array}{c}0.992 \\
(1.507) \\
\end{array}$ & $\begin{array}{c}0.920 \\
(1.576) \\
\end{array}$ & $\begin{array}{l}-0.423 \\
(0.765)\end{array}$ \\
\hline$\omega$ & $\begin{array}{c}36.658^{* *} \\
(9.796)\end{array}$ & $\begin{array}{c}38.088^{* *} \\
(8.016)\end{array}$ & $\begin{array}{l}0.016^{*} \\
(0.008)\end{array}$ \\
\hline GARCH/GJR $\alpha$ & $\begin{array}{l}0.090 * * \\
(0.003)\end{array}$ & $\begin{array}{l}0.086^{* *} \\
(0.004)\end{array}$ & -- \\
\hline GARCH/GJR $\beta$ & $\begin{array}{l}0.918 * * \\
(0.003)\end{array}$ & $\begin{array}{c}0.929 * * \\
(0.002)\end{array}$ & -- \\
\hline GJR $\gamma$ & -- & $\begin{array}{c}-0.023^{* *} \\
(0.006)\end{array}$ & -- \\
\hline EGARCH $\alpha$ & -- & -- & $\begin{array}{l}0.050^{* *} \\
(0.004)\end{array}$ \\
\hline EGARCH $\gamma$ & -- & -- & $\begin{array}{c}0.086^{* *} \\
(0.003)\end{array}$ \\
\hline EGARCH $\beta$ & -- & -- & $\begin{array}{l}0.994^{* *} \\
(0.001)\end{array}$ \\
\hline \multicolumn{4}{|l|}{ Diagnostics } \\
\hline AIC & 12.261 & 12.261 & 12.246 \\
\hline $\mathrm{BIC}$ & 12.271 & 12.272 & 12.257 \\
\hline $\begin{array}{l}\text { Jarque-Bera } \\
\text { [p-value] }\end{array}$ & $\begin{array}{c}11515.91 \\
{[0.000]}\end{array}$ & $\begin{array}{c}12437.80 \\
{[0.000]}\end{array}$ & $\begin{array}{c}11658.98 \\
{[0.000]}\end{array}$ \\
\hline $\begin{array}{l}\text { Causality F test } \\
\text { [p-value] }\end{array}$ & $\begin{array}{c}4.650 \\
{[0.003]}\end{array}$ & $\begin{array}{c}3.270 \\
{[0.020]}\end{array}$ & $\begin{array}{c}3.706 \\
{[0.011]}\end{array}$ \\
\hline
\end{tabular}

Notes: The dependent variable is Korean tourist arrivals to Taiwan. Numbers in parentheses are standard errors. AIC and BIC denote the Akaike Information Criterion and Schwarz Bayesian Information Criterion, respectively. $* *$ and $*$ denote the estimated coefficients are statistically significant at the $1 \%$ and $5 \%$ levels, respectively. 
Table 6: Estimated Conditional Mean (HAR(1)) and Conditional Volatility Models for Korean Won / New Taiwan \$

\begin{tabular}{|c|c|c|c|}
\hline Parameters & GARCH & GJR & EGARCH \\
\hline$\phi_{1}$ & $\begin{array}{l}0.0203 \\
(0.011)\end{array}$ & $\begin{array}{l}0.024^{*} \\
(0.010)\end{array}$ & $\begin{array}{c}0.023 * * \\
(0.003)\end{array}$ \\
\hline$\phi_{21}$ & $\begin{array}{l}0.999 * * \\
(0.0003)\end{array}$ & $\begin{array}{l}0.999 * * \\
(0.0003)\end{array}$ & $\begin{array}{l}0.999 * * \\
(0.0001)\end{array}$ \\
\hline$\phi_{22}$ & $\begin{array}{c}8.23 \mathrm{E}-6 \\
(5.39 \mathrm{E}-06) \\
\end{array}$ & $\begin{array}{c}8.40 \mathrm{E}-06 \\
(5.36 \mathrm{E}-06)\end{array}$ & $\begin{array}{l}1.17 \mathrm{E}-05^{* *} \\
(2.91 \mathrm{E}-06)\end{array}$ \\
\hline$\omega$ & $\begin{array}{c}0.0001^{* *} \\
(6.98 \mathrm{E}-06)\end{array}$ & $\begin{array}{c}0.0001^{* *} \\
(6.22 \mathrm{E}-06)\end{array}$ & $\begin{array}{c}-0.1226^{* *} \\
(0.003)\end{array}$ \\
\hline GARCH/GJR $\alpha$ & $\begin{array}{l}0.081^{* *} \\
(0.002)\end{array}$ & $\begin{array}{c}0.088 * * \\
(0.003)\end{array}$ & -- \\
\hline GARCH/GJR $\beta$ & $\begin{array}{c}0.918^{* *} \\
(0.002)\end{array}$ & $\begin{array}{l}0.926^{* *} \\
(0.001)\end{array}$ & -- \\
\hline GJR $\gamma$ & -- & $\begin{array}{c}-0.032 * * \\
(0.004)\end{array}$ & -- \\
\hline EGARCH $\alpha$ & -- & -- & $\begin{array}{c}0.145 * * \\
(0.003)\end{array}$ \\
\hline EGARCH $\gamma$ & -- & -- & $\begin{array}{c}0.037 * * \\
(0.003)\end{array}$ \\
\hline EGARCH $\beta$ & -- & -- & $\begin{array}{l}0.991 * * \\
(0.001) \\
\end{array}$ \\
\hline \multicolumn{4}{|l|}{ Diagnostics } \\
\hline AIC & -1.460 & -1.462 & -1.448 \\
\hline $\mathrm{BIC}$ & -1.454 & -1.456 & -1.441 \\
\hline $\begin{array}{l}\text { Jarque-Bera } \\
\text { [p-value] }\end{array}$ & $\begin{array}{c}28387.47 \\
{[0.000]} \\
\end{array}$ & $\begin{array}{c}27050.33 \\
{[0.000]} \\
\end{array}$ & $\begin{array}{c}23612.19 \\
{[0.000]} \\
\end{array}$ \\
\hline
\end{tabular}

Notes: The dependent variable is the Korean Won / NT\$ exchange rate. Numbers in parentheses are standard errors. The log-moment condition is necessarily satisfied as the second moment condition is satisfied. AIC and BIC denote the Akaike Information Criterion and Schwarz Bayesian Information Criterion, respectively.

** and * denote the estimated coefficients are statistically significant at the $1 \%$ and $5 \%$ levels, respectively. 
Table 7: Estimated Conditional Mean $(\operatorname{HAR}(1,7))$ and Conditional Volatility Models

for Korean Won / New Taiwan \$

\begin{tabular}{|c|c|c|c|}
\hline Parameters & GARCH & GJR & EGARCH \\
\hline$\phi_{1}$ & $\begin{array}{c}0.022 \\
(0.012)\end{array}$ & $\begin{array}{c}0.024 \\
(0.012)\end{array}$ & $\begin{array}{l}0.026 * * \\
(0.002)\end{array}$ \\
\hline$\phi_{21}$ & $\begin{array}{l}0.905^{* *} \\
(0.010)\end{array}$ & $\begin{array}{l}0.906 * * \\
(0.010)\end{array}$ & $\begin{array}{c}0.895^{* *} \\
(0.011)\end{array}$ \\
\hline$\phi_{22}$ & $\begin{array}{c}4.87 \mathrm{E}-06 \\
(7.55 \mathrm{E}-06)\end{array}$ & $\begin{array}{c}3.13 E-06 \\
(7.96 E-06)\end{array}$ & $\begin{array}{c}1.74 \mathrm{E}-05^{* *} \\
(6.47 \mathrm{E}-06)\end{array}$ \\
\hline$\phi_{31}$ & $\begin{array}{c}0.094^{* *} \\
(0.010)\end{array}$ & $\begin{array}{c}0.093^{* *} \\
(0.010)\end{array}$ & $\begin{array}{c}0.104 * * \\
(0.010)\end{array}$ \\
\hline$\phi_{32}$ & $\begin{array}{c}5.90 \mathrm{E}-06 \\
(1.02 \mathrm{E}-05)\end{array}$ & $\begin{array}{c}9.00 \mathrm{E}-06 \\
(1.07 \mathrm{E}-05)\end{array}$ & $\begin{array}{c}-1.00 \mathrm{E}-05 \\
(7.21 \mathrm{E}-06)\end{array}$ \\
\hline$\omega$ & $\begin{array}{c}0.0001^{* *} \\
(6.51 \mathrm{E}-06)\end{array}$ & $\begin{array}{c}0.0001^{* *} \\
(5.89 \mathrm{E}-06)\end{array}$ & $\begin{array}{c}-0.158^{* *} \\
(0.003)\end{array}$ \\
\hline GARCH/GJR $\alpha$ & $\begin{array}{c}0.077 * * \\
(0.002)\end{array}$ & $\begin{array}{l}0.083^{* *} \\
(0.003)\end{array}$ & -- \\
\hline GARCH/GJR $\beta$ & $\begin{array}{c}0.922 * * \\
(0.002)\end{array}$ & $\begin{array}{l}0.930^{* *} \\
(0.001)\end{array}$ & -- \\
\hline GJR $\gamma$ & -- & $\begin{array}{c}-0.030 * * \\
(0.004)\end{array}$ & -- \\
\hline EGARCH $\alpha$ & -- & -- & $\begin{array}{l}0.178 * * \\
(0.003)\end{array}$ \\
\hline EGARCH $\gamma$ & -- & -- & $\begin{array}{l}0.029 * * \\
(0.003)\end{array}$ \\
\hline EGARCH $\beta$ & -- & -- & $\begin{array}{l}0.988 * * \\
(0.0004)\end{array}$ \\
\hline \multicolumn{4}{|l|}{ Diagnostics } \\
\hline AIC & -1.472 & -1.475 & -1.456 \\
\hline BIC & -1.464 & -1.466 & -1.447 \\
\hline $\begin{array}{l}\text { Jarque-Bera } \\
\text { [p-value] }\end{array}$ & $\begin{array}{c}28461.48 \\
{[0.000]} \\
\end{array}$ & $\begin{array}{c}26702.17 \\
{[0.000]} \\
\end{array}$ & $\begin{array}{c}27438.20 \\
{[0.000]} \\
\end{array}$ \\
\hline
\end{tabular}

Notes: The dependent variable is the Korean Won / NT\$ exchange rate. Numbers in parentheses are standard errors. The log-moment condition is necessarily satisfied as the second moment condition is satisfied. AIC and BIC denote the Akaike Information Criterion and Schwarz Bayesian Information Criterion, respectively.

** denotes the estimated coefficient is statistically significant at the $1 \%$ level. 
Table 8: Estimated Conditional Mean $(\operatorname{HAR}(1,7,28))$ and Conditional Volatility Models for Korean Won / New Taiwan \$

\begin{tabular}{|c|c|c|c|}
\hline Parameters & GARCH & GJR & EGARCH \\
\hline$\phi_{1}$ & $\begin{array}{c}0.019 \\
(0.013)\end{array}$ & $\begin{array}{c}0.022 \\
(0.013)\end{array}$ & $\begin{array}{c}0.041 * * \\
(0.002)\end{array}$ \\
\hline$\phi_{21}$ & $\begin{array}{l}0.898 * * \\
(0.011)\end{array}$ & $\begin{array}{l}0.899 * * \\
(0.011)\end{array}$ & $\begin{array}{l}0.902 * * \\
(0.001)\end{array}$ \\
\hline$\phi_{22}$ & $\begin{array}{c}5.51 \mathrm{E}-06 \\
(7.46 \mathrm{E}-06)\end{array}$ & $\begin{array}{c}3.42 \mathrm{E}-06 \\
(7.90 \mathrm{E}-06)\end{array}$ & $\begin{array}{l}-5.41 \mathrm{E}-07 \\
(6.74 \mathrm{E}-06)\end{array}$ \\
\hline$\phi_{31}$ & $\begin{array}{c}0.118^{* *} \\
(0.014)\end{array}$ & $\begin{array}{c}0.116^{* *} \\
(0.014)\end{array}$ & $\begin{array}{l}0.095^{* *} \\
(0.001)\end{array}$ \\
\hline$\phi_{32}$ & $\begin{array}{c}2.70 \mathrm{E}-06 \\
(1.58 \mathrm{E}-05)\end{array}$ & $\begin{array}{c}5.35 \mathrm{E}-06 \\
(1.64 \mathrm{E}-05)\end{array}$ & $\begin{array}{c}4.44 \mathrm{E}-05^{* *} \\
(1.00 \mathrm{E}-05)\end{array}$ \\
\hline$\phi_{41}$ & $\begin{array}{c}-0.017 * * \\
(0.006)\end{array}$ & $\begin{array}{c}-0.016^{*} \\
(0.007)\end{array}$ & $\begin{array}{l}0.001^{* *} \\
(0.0001)\end{array}$ \\
\hline$\phi_{42}$ & $\begin{array}{c}4.31 \mathrm{E}-06 \\
(1.66 \mathrm{E}-05)\end{array}$ & $\begin{array}{c}5.28 \mathrm{E}-06 \\
(1.64 \mathrm{E}-05)\end{array}$ & $\begin{array}{c}-3.43 \mathrm{E}-05^{* *} \\
(8.65 \mathrm{E}-06)\end{array}$ \\
\hline$\omega$ & $\begin{array}{c}0.0001^{* *} \\
(6.80 \mathrm{E}-06)\end{array}$ & $\begin{array}{c}0.0001^{* *} \\
(6.15 \mathrm{E}-06)\end{array}$ & $\begin{array}{c}-0.137 * * \\
(0.003)\end{array}$ \\
\hline GARCH/GJR $\alpha$ & $\begin{array}{c}0.078^{* *} \\
(0.002)\end{array}$ & $\begin{array}{c}0.084^{* *} \\
(0.003)\end{array}$ & -- \\
\hline GARCH/GJR $\beta$ & $\begin{array}{c}0.921 * * \\
(0.002)\end{array}$ & $\begin{array}{c}0.929 * * \\
(0.002)\end{array}$ & -- \\
\hline GJR $\gamma$ & -- & $\begin{array}{c}-0.031^{* *} \\
(0.004)\end{array}$ & -- \\
\hline EGARCH $\alpha$ & -- & -- & $\begin{array}{c}0.156^{* *} \\
(0.003)\end{array}$ \\
\hline EGARCH $\gamma$ & -- & -- & $\begin{array}{c}0.022 * * \\
(0.003)\end{array}$ \\
\hline EGARCH $\beta$ & -- & -- & $\begin{array}{l}0.990 * * \\
(0.0004) \\
\end{array}$ \\
\hline \multicolumn{4}{|l|}{ Diagnostics } \\
\hline AIC & -1.466 & -1.468 & -1.450 \\
\hline $\mathrm{BIC}$ & -1.456 & -1.457 & -1.440 \\
\hline $\begin{array}{l}\text { Jarque-Bera } \\
\text { [p-value] }\end{array}$ & $\begin{array}{c}27914.10 \\
{[0.000]}\end{array}$ & $\begin{array}{c}26463.97 \\
{[0.000]}\end{array}$ & $\begin{array}{c}26061.30 \\
{[0.000]}\end{array}$ \\
\hline
\end{tabular}

Notes: The dependent variable is the Korean Won / NT\$ exchange rate. Numbers in parentheses are standard errors. The log-moment condition is necessarily satisfied as the second moment condition is satisfied. AIC and BIC denote the Akaike Information Criterion and Schwarz Bayesian Information Criterion, respectively.

** and * denote the estimated coefficients are statistically significant at the $1 \%$ and $5 \%$ levels, respectively. 